\title{
FUNDAMENTOS FILOSÓFICOS E IMPLICANCIAS SUBJETIVAS DE LA NOCIÓN DE CUERPO EN LAS TÉCNICAS DE REPRODUCCIÓN HUMANA ASISTIDA
}

\section{PHILOSOPHICAL FUNDAMENTS AND SUBJETIVE IMPLICATIONS OF THE NOTION OF BODY IN ASSISTED HUMAN REPRODUCTIVE TECHNIQUES}

\section{Ana Cecilia González (UBA, CONICET)}

\begin{abstract}
RESUMEN
El desarrollo de las Técnicas de Reproducción Humana Asistida (TRHA), supone una transformación fundamental en el modo concebir y tratar el cuerpo humano, que tiene por correlato importantes incidencias sobre la subjetividad. Este aspecto suele quedar en segundo plano frente a sus consecuencias para la conformación de la familia. En este artículo, en cambio, analizaremos los fundamentos filosóficos de la concepción del cuerpo en la que esta tecnología se sustenta, - y que, a su vez, las TRHA han contribuido a consolidar-, la cual tiene un inicio y una evolución en la historia del pensamiento occidental. Además, ya en pleno siglo XXI, con el espectacular desarrollo de la biomedicina, esa manera de concebir el cuerpo no sólo trae aparejados grandes cambios a nivel de la regulación jurídica, sino que tiene fuerte impacto sobre la subjetividad, según unas coordenadas que procuramos explorar en este artículo.
\end{abstract}

Palabras claves: Técnicas de Reproducción Humana Asistida, cuerpo, subjetividad

\section{ABSTRACT}

The development of Assisted Human Reproductive Techniques (AHRT) implies a fundamental transformation in the way we conceive and treat the human body, which has important influence on subjectivity. This aspect is frequently left aside as compared to its consequences on family configuration. This paper, on the contrary, is set to analyse the philosophical foundations of the body conception that gives support to such techniques and that AHRT, at their turn, have contributed to consolidate-, a conception with a precise origin and evolution in the history of Western philosophy. Also, in $21^{\text {st }}$ century, together with the spectacular development of biomedicine, such conception of the body not only brings considerable transformations in legal regulation, but also has strong impact on subjectivity, in ways we mean to explore in this paper.

Keywords: Assisted Human Reproductive Techniques, body, subjectivity

\section{Introducción}

El impacto más notorio de las Técnicas de Reproducción Humana Asistida (TRHA) se inscribe en un proceso histórico de mutación de la normatividad sexual que se remonta a los años '60 (Cosse, 2010) y que ha conmocionado la estructura de la institución que sirve de soporte al proceso de humanización y constitución subjetiva. Así, el desarrollo de las TRHA ha implicado profundos cambios en las maneras en que se organiza y regula la vida familiar. Pero sus efectos no sólo atañen a la vida en común, con la familia como estructura simbólica básica, sino también a la vida en el sentido biológico del término, y más específicamente, a la vida en tanto y en cuanto ésta tiene lugar mediante la reproducción biológica de los cuerpos. Teniendo esto en cuenta, hay otra transformación fundamental correlativa del 
desarrollo de las TRHA, que suele pasar desapercibida, y es la que analizaremos en este artículo. En lo que sigue desarrollaremos dos tesis: 1) las TRHA se sustentan en una determinada concepción filosófica del cuerpo - que, a su vez, han contribuido a consolidar-, que tiene un inicio y una evolución en la historia del pensamiento occidental; 2) ya en pleno siglo XXI, con el espectacular desarrollo de la biomedicina, esa manera de concebir el cuerpo no sólo trae aparejados grandes cambios a nivel de la regulación jurídica, sino que tiene fuertes incidencias sobre lo que el psicoanalista Jacques Lacan llamaba "la subjetividad de la época"1 (Lacan, 2003: 309).

\section{Del cuerpo al gameto, o de Descartes a la biopolítica}

La noción de cuerpo en la que se sustenta, no sólo las TRHA, sino el pujante desarrollo de la medicina contemporánea en general, tiene su origen en el siglo XVII, y es fruto de la elaboración filosófica de René Descartes. Aunque la teoría cartesiana es harto conocida, conviene resumir aquí sus principios fundamentales, ya que está en la base del paradigma mecanicista ${ }^{2}$ y sus avatares ulteriores.

Descartes parte de la distinción de dos sustancias y retoma el hilemorfismo aristotélico para caracterizarlas: "La materia del hombre es su cuerpo; su forma es su alma razonable; es entonces por su forma que él es un ser razonable, y por su razón que es un hombre" (Descartes, 1965: 46) ${ }^{3}$. Según esta distinción jerárquica la res cogitans es poseedora de autonomía y principio de acción (o "agencia", según el anglicismo adoptado en la academia contemporánea), mientras que la res extensa, por el contrario, es una materia pasiva y, por lo tanto, subordinada a la primera.

En cuanto a la noción de cuerpo, que es lo que aquí nos interesa, hace falta detenerse en las propiedades de la sustancia extensa de la que aquel forma parte. En palabras de Descartes: “(...) por cuerpo entiendo todo aquello que puede ser delimitado por alguna figura; que puede ser contenido en algún lugar y llenar un espacio de tal modo que cualquier otro cuerpo quede excluido de él; que puede ser sentido, o por el tacto, o por la vista, o por el oído, o por el gusto, o por el olfato; que puede ser movido de varias maneras, no por sí mismo, sino por algo extraño que lo toca y del que recibe el impulso. Ya que, si tuviera en sí el poder de moverse, de sentir y de pensar, no creo en absoluto que se le debieran atribuir estas excelencias a la naturaleza corporal; al contrario, me extrañaría mucho ver que semejantes capacidades se encontraran en ciertos cuerpos" (Descartes, 2010: Meditación II) ${ }^{4}$.

De esta noción de cuerpo son destacables tres aspectos. En primer lugar, la cesura que implica respecto del cuerpo de la tradición cristiana, marcado fuertemente por la prohibición de modificar lo que es fruto de la creación divina. El cuerpo cartesiano, en cambio, reducido a mera extensión, no sólo es pasivo, sino que es pasible de descomposición y manipulación, es decir, que se lo puede tratar del mismo modo que a la materia inerte. En segundo término, importa retener que el cuerpo cartesiano es a la vez condición y efecto del nacimiento de la ciencia en su acepción moderna, con la exigencia de

\footnotetext{
${ }^{1}$ Este sintagma, de raíz hegeliana, designa la relación entre la subjetividad y las formas histórico-sociales que cobra "el malestar en la cultura", tomando el título de un célebre texto de Sigmund Freud.

${ }^{2}$ Es preciso señalar que, si bien este paradigma se corresponde con la lectura más difundida de la teoría cartesiana, constituyendo su interpretación clásica, en la segunda mitad del siglo XX, y atento a la crítica de dicho paradigma y sus consecuencias ético-políticas, Jean-Luc Nancy, se ha consagrado a pensar una ontología desde el cuerpo, procurando establecer otra lectura de Descartes. Más específicamente, el filósofo contemporáneo sostiene que hay una idea de unidad del cuerpo y el alma en Descartes que ha quedado en segundo plano, y que Nancy toma como punto de partida para su propia reflexión en clave post-metafísica, cf. Nancy, J.-L. (2010: 58) indicios sobre el cuerpo. Extensión del alma. Buenos Aires: Ediciones La Cebra.

3 “La matière de l'homme est son corps; sa forme est son âme raisonnable; c'est donc par sa forme qu'il est un être raisonnable, et par sa raison qu'il est un homme." Descartes, R: Discours de la méthode, nota n.1 a pie de página de la página 46. París: J. Vrin, 1965 [1637]. Esta no está incluida en la edición en castellano, por lo que la he tomado de la edición en francés.

${ }^{4}$ Por tratarse de una versión editada para libro electrónico Kindle de Discurso del método y Meditaciones metafísicas no es posible consignar el número de página, en cambio he consignado la parte de la que se extrae la cita. La referencia de la edición consta en la bibliografía, al igual que el resto de fuentes citadas.
} 
objetividad, experimentación y verificación. La consecuencia de este cambio es el despedazamiento del cuerpo viviente, definido por Descartes como partes extra partes. Este modo de aproximación inaugura la perspectiva mecanicista, según la cual el cuerpo es objeto de observación, medición, disección y manipulación, reducido a las leyes físicas y químicas de la materia. El despedazamiento del cuerpo se produce en función de una metáfora específica, porque el pensamiento de Descartes está plagado de analogías con máquinas hidráulicas, autómatas y, ante todo, relojes. En efecto, lo que el filósofo buscaba en el cuerpo era un reloj, es decir, una máquina conformada como un conjunto de partes que pueden desarmarse y volverse a armar, y cuyo funcionamiento depende de la precisión del montaje.

Tres siglos más tarde, el cuerpo maquinal cartesiano, partes extra partes, tiene plena vigencia como fundamento de saberes, prácticas y técnicas, entre ellas las TRHA. En efecto, el espectacular desarrollo de la medicina, en alianza con la microbiología, tuvo lugar como un proceso que se inicia con las primeras autopsias y avanza inexorablemente en el desmontaje de piezas cada vez más pequeñas, hasta alcanzar el nivel molecular. Así, los anatomistas contemporáneos de Descartes, convirtieron el cuerpomáquina en cadáver, inaugurando la exploración del cuerpo humano hasta sus más recónditas intimidades.

Michel Foucault recorrió este camino, desde El nacimiento de la clínica (1978) al concepto de biopolítica, es decir, del médico que ausculta, mide y disecciona la extensión del cuerpo, a la modalidad contemporánea del poder, organizado como control sobre la vida. En sus palabras, la biopolítica se define como "(...) lo que hace entrar a la vida y sus mecanismos en el dominio de los cálculos explícitos y convierte al poder-saber en un agente de transformación de la vida humana" (Foucault, 2008: 135, las itálicas con mías). En la estela abierta por Foucault, y poniendo énfasis en la noción de vida, Giorgio Agamben ha postulado que la "inclusión de la nuda vida en el reino de la política constituye el núcleo originario -aunque históricamente escondido- del poder soberano" (Agamben, 1998: 6). Es decir, que la gestión del cuerpo biopolítico es la actividad constitutiva del cuerpo soberano, y no desde el siglo XVIII como planteaba el pensador francés, sino todo a lo largo de la historia. Lo característico de nuestro tiempo sería entonces la creciente importancia que adquiere una noción en particular, la de "nuda vida" - o "zoé" - que reduce su esencia al funcionamiento biomecánico. Dicho de otro modo: en esta configuración de saber y poder, la vida es reducida a un conjunto de mecanismos susceptibles de cálculo o una serie de "algoritmos", retomando la expresión del genetista François Jacob.

El límite de la conceptualización de Agamben es que, enfatizando la articulación entre nuda vida y poder soberano, deja en segundo plano otro aspecto fundamental de la caracterización foucaultiana de la biopolítica, como es la conformación de la subjetividad en el marco de un determinado paradigma de poder. La noción de subjetividad es una pieza central en la teoría biopolítica, porque designa el punto en que el poder deja de ser meramente represivo y/o disciplinario, para convertirse en un poder productivo, es decir, que positiviza determinadas formas de subjetivación. Justamente, el problema de la subjetivación y los modos de (auto)gobierno están en el centro del planteamiento de Nikolas Rose (2012). Respecto del cuerpo maquinal cartesiano, este autor subraya que la "biomedicina contemporánea" está fundada en la creencia de que cualquier proceso vital puede ser explicado y modificado en base a las propiedades físicas de los componentes y sus interacciones, como si se tratara de un electrodoméstico. En el siguiente apartado tendremos en cuenta su propuesta para analizar los efectos subjetivos de este modo de entender y tratar el cuerpo.

\section{Biomedicina contemporánea: regulación jurídica e implicancias subjetivas}

Rose se ocupa de describir los correlatos subjetivos de la configuración de poder denominada biopolítica, y para ello investiga el modo en que la biomedicina y la neurociencia están transformando las creencias sobre nuestra identidad y los lenguajes que usamos para auto-interpretarnos o juzgarnos. Vale insistir que el poder biopolítico es ante todo un poder productivo, que genera subjetividades y cuerpos a medida. Asimismo, genera y regula modalidades de lazo social, toda vez que los individuos 
se reúnen y organizan en función de la reivindicación de derechos biológicos o biomédicos. Por ejemplo, tal ha sido el caso de la demanda de acceso a las TRHA en Argentina, que culminó con una legislación (Ley 26.862) que les concede estatuto de derecho para toda la población mayor de edad, sin discriminación de género o estado civil.

Retomando el planteo de Rose, él describe dos caracteres fundamentales de la biomedicina del siglo XXI. El primero es el pasaje del nivel molar al molecular de la escala de la representación del cuerpo. Lo impactante es que, con la "molecularización", se ponen en juego los límites del cuerpo como soporte no sólo del sujeto, sino también de la persona jurídica. De hecho, ante los avances de la biomedicina, el derecho se ha visto llevado a distinguir entre cuerpo humano, de un lado, y elementos y productos del cuerpo humano, del otro (Iacub, 2002). Entre los segundos se cuenta el embrión extracorpóreo, que, mediante la técnica denominada "fertilización in vitro", es producido y "cultivado" en laboratorio durante 4 o 5 días (y todo hace pensar que este lapso se hará paulatinamente más extenso). El mismo estatuto tienen los gametos, y tanto unos como los otros pueden ser crioconservados indefinidamente.

La progresiva fragmentación del cuerpo por la incidencia de la ciencia trae aparejados efectos subjetivos de alto impacto. Entre otros, el soporte corporal en su aprehensión cotidiana de unidad amenaza con desaparecer, de modo tal que la relación espontánea entre identidad y cuerpo trastabilla. En consecuencia, debe ser garantizada por un aparato jurídico cada vez más sofisticado. Dicha aprehensión cotidiana y espontánea de unidad e identidad corporal ha sido objeto de estudio por parte de la psicología evolutiva, la teoría de la Gestalt y el psicoanálisis. Jacques Lacan propuso la teoría del "estadio del espejo" para describir la operación en la que se funda dicha unidad. De entrada, y debido a lo prematuro de la cría human, el infans no experimenta el cuerpo como uno, sino como partes disjuntas, de difícil coordinación. La unidad corporal se adquiere mediante una operación psíquica que consiste en la identificación con una imagen, que es la que devuelve el espejo, para júbilo del niño que la contempla. Pero más allá del espejo, la que importa es la imagen conferida por el otro que cuida del infans. La unidad corporal se toma prestada, por así decirlo, del semejante. Sin embargo, la imago del cuerpo fragmentado, que es el reverso de la identificación especular, acechará siempre a la unidad corporal y yoica. Así lo demuestran el contenido de los sueños de angustia, algunas presentaciones psicopatológicas y diversas manifestaciones artísticas, señala Lacan -y a esta lista cabría añadir las fantasías de la ciencia ficción.

Entonces, la fragmentación corporal impulsada por la ciencia impacta de lleno en este resorte subjetivo fundamental, y el proceso tiene por correlato, ante todo, la angustia. Esto se verifica en la proliferación de discursos que representan esfuerzos por contrarrestar dicha fragmentación, promoviendo un ideal que ubica el cuerpo del lado del ser. El auge de las filosofías y prácticas corporales orientales, que preservan la unidad del cuerpo y el alma, puede interpretarse de este modo, y también la tiranía narcisista del cuidado corporal. Se trata de intentos de paliar los efectos de la división cartesiana del cuerpo y sus derroteros subjetivos contemporáneos.

Justamente, el segundo rasgo descrito por Rose como característico de la subjetividad en la era de la biomedicina, es la transformación de las creencias acerca de la identidad y los juicios sobre sí mismo en relación con el cuerpo. El autor sostiene que "(...) nuestro propio soma, nuestro propio cuerpo ha devenido la característica constitutiva de nuestra subjetividad" (Rose, 2013: 28), haciendo prevalecer su acepción biológica. La dimensión sagrada del cuerpo, sostenida largamente por la tradición judeo cristiana cede el paso a una concepción organicista que impregna fuertemente el léxico cotidiano y el modo en que nos pensamos a nosotros mismos. Esto significa que la subjetividad y la identidad se configuran en torno a nociones tomadas de la biología, a tono con el cientificismo como ideología dominante de la época. Basta una mirada a la prensa gráfica para verificar que abundan los ejemplos en los que cualquier patología, o incluso la conducta compleja, pretenden ser explicadas mediante un gen o mecanismo biológico específico -y pese a que el proyecto Genoma Humano haya demostrado lo poco fundado de estas predicciones-. 
Las TRHA están implicadas en los dos aspectos descritos por Rose, puesto que llevan al extremo la desaparición de la unidad del cuerpo como soporte del ser, y al mismo tiempo reducen la identidad a un marcador biológico, haciendo prevalecer la evidencia genética. Por ejemplo, la fertilización in vitro con donación de gametos, ya sean óvulos o espermatozoides, plantea toda una serie de preguntas en torno a la identidad: ¿el donante debe permanecer anónimo? El niño nacido por esta técnica ¿tiene derecho a conocer la identidad del donante? ¿Configura esta información un dato relevante para la constitución de su propia identidad? ¿Qué impacto puede tener en su conformación subjetiva? No son preguntas fáciles de resolver, y cada país lo ha hecho con su propia legislación ${ }^{1}$. En el caso de Argentina, ha prevalecido la noción de "anonimato relativo" - el sujeto nacido bajo tales circunstancias puede conocer la identidad del donante mediando una serie de condiciones (Herrera, Carmelo y Picasso, 2015) -, mientras que, en otros países, como Francia, por ejemplo, el anonimato es absoluto.

En general, las TRHA se asocian con la serie de normas jurídicas para regular su accesibilidad y con las nuevas configuraciones familiares que contextualizan su utilización (en el caso de Argentina la ley que garantiza el acceso a las TRHA, de un lado, y la ley de Matrimonio Igualitario y la reforma del Código Civil, del otro). En cambio, se ha prestado menor atención a las implicancias jurídicas y subjetivas a nivel de la relación con el cuerpo.

Como hemos argumentado hasta aquí, la corporalidad maquinal y desmontable de Descartes, llevada al extremo, modifica lo que entendemos por "cuerpo", afectando un soporte fundamental del proceso de subjetivación. Se trata de una conmoción que plantea la pregunta por los límites corporales, ante la posibilidad creciente de sustitución de órganos, fabricación mediante impresoras 3D, crioconservación de material humano, etc. Tal como señala Marcela Iacub "cuerpo humano" ha dejado de ser una categoría de inmediatez biológica para convertirse en una categoría jurídica. Esta categoría se define por el conjunto de derechos y obligaciones de las personas vivas y fallecidas que forman parte del circuito de intercambio de elementos y productos corporales, creado por las leyes bioéticas (relativas a la donación y circulación de sangre, órganos, gametos, embriones, etc.) (Iacub, 2002). Al mismo tiempo, y de manera concomitante, la identidad de la persona jurídica sólo puede ser garantizada por esas mismas leyes. De modo que el aparato legal configura, en última instancia, un sistema de regulación y control que nos hace vivir, morir y permanecer idénticos a nosotros mismos. Se inaugura así una nueva economía política de la vida, que va incluso más allá de lo entrevisto por Foucault, afirma Iacub. La biopolítica ya no es (exclusivamente) el poder sobre los cuerpos y las poblaciones según las categorías de análisis propuestas por el filósofo-, sino el poder sobre el "material humano". De suerte que el ser humano, su cuerpo, e incluso la especie, dejan de ser datos a priori, y se convierten en horizontes a construir con dicho "material humano".

\section{El siglo XXI, entre el barco de Teseo y la deriva postorgánica}

Ya en pleno siglo XXI, un viejo tema filosófico, el apólogo del barco de Teseo, adquiere un nuevo e inquietante relieve. Como es sabido, Teseo es un héroe de la mitología griega que tiene la tarea de enfrentar al Minotauro en su laberinto. Cuando, contra todo pronóstico, y no sin la ayuda de los dioses y del hilo de Ariadna, Teseo regresa victorioso a Atenas, los ciudadanos de la polis deciden conservar el barco como símbolo de la hazaña. Con el tiempo el barco se deteriora, y entonces los atenienses van reemplazando los maderos viejos por unos nuevos. La paradoja, referida por Plutarco a finales del siglo I d. C. en Vidas paralelas, ha suscitado el debate por siglos, y hasta la actualidad: el barco así reconstruido ¿es o no el barco de Teseo? En el siglo XVII, Thomas Hobbes le sumó complejidad al tener en cuenta la variable temporal (Noonan, 2003). Su planteo se denomina "el argumento del puzzle" y plantea que, si se hubieran guardado las maderas y partes viejas del barco, y se lo hubiera reconstruido, por ejemplo, cuatrocientos años más tarde, entonces habría dos barcos de Teseo, el reconstruido en la Antigüedad con maderas de repuesto, y el otro, hecho con las maderas originales pero cuatro siglos más tarde. En consecuencia, el apólogo sirve para abordar dos problemáticas relativas a la identidad. Por un lado, la relación entre el todo y sus partes, que desemboca en una cuestión cuantitativa acerca de qué porcentaje de piezas originales debe conservar un objeto para que

${ }^{1}$ Cf. Mariage des personnes de même sexe et homoparentalité, Informe de legislación comparada encargado por el senador Jean-Pierre Sueur. http://www.senat.fr/notice-rapport/2012/lc229-notice.html 
pueda seguir siendo considerado el mismo, es decir, para que se preserve su identidad. Por otra parte, está la cuestión de la continuidad espacio-temporal, ya que se puede argumentar que sólo el barco reconstruido con maderos nuevos es el barco de Teseo, porque guarda dicha continuidad, mientras que el segundo, aunque use las maderas originales, no contempla este principio y por lo tanto no mantendría la identidad.

Si bien el planteo de esta paradoja se refiere a un artefacto, la concepción cartesiana del cuerpo humano como sustancia extensa que, justamente, lo trata como un artefacto más, habilita que el planteo se traslade a los avatares biomédicos contemporáneos. Por ejemplo, en lo que respecta específicamente a las TRHA, recientemente el Parlamento británico aprobó el uso de una técnica de trasplante de orgánulos celulares, reemplazando el ADN mitocondrial del ovocito de una mujer por el de otra, con el fin de evitar enfermedades que se transmiten por esta vía (Guimón \& Prats, 3 de febrero de 2015). Este tipo de técnica "reprogenética" - a saber, la manipulación genética con fines terapéuticos, combinada con las TRHA- supone una suerte de "puzzle" de genes, y podría eventualmente desembocar en planteos identitarios al modo del apólogo de Teseo. En este caso sólo se reemplazó un orgánulo celular dañado, pero ¿y si fueran dos, o tres, o más? ¿Cuál es el límite? ¿Hasta dónde se preserva el principio de identidad? ¿Con qué criterio se establece? Por supuesto, lo mismo puede plantearse para el reemplazo de órganos o piezas del cuerpo impresas en 3D, mientras avanza la generación de órganos a partir de células madre.

Hace doscientos años, la imaginación de Mary Shelley creó a Víctor Frankenstein, el médico decimonónico que se atrevió a manipular el secreto de la vida, animando la materia inerte y engendrando así el famoso monstruo, hecho con partes de diversos cadáveres. En la segunda década del siglo XXI, este proyecto fantástico parece a punto de realizarse por una vía más sofisticada, la de la síntesis del viviente realizada in vitro, con partes de escala molecular.

Aunque con frecuencia se ha identificado a Víctor Frankenstein con un Prometeo moderno, que se atreve a robar el secreto de la vida y paga el precio por su transgresión, la antropóloga Paula Sibilia (2005) propone distinguir dos tradiciones científicas, una que denomina prometeica, y otra llamada fáustica, según el célebre personaje de la novela de Johann Wolfgang von Goethe. Sibilia retoma un planteo del epistemólogo portugués Heminio Martins (2011), quien sostiene que la tecno-ciencia actual tiene vocación fáustica, porque pretende superar los límites de la condición humana. En efecto, desde diversos frentes del ámbito de la cultura se ha planteado que el cuerpo humano como configuración orgánica está condenado a la obsolescencia. En consecuencia, prosigue Sibilia, “(...) ciertas tendencias neo-gnósticas rechazan el carácter orgánico y material del cuerpo humano y pretenden superarlo, buscando un ideal aséptico, artificial, virtual e inmortal" (Sibilia, 2005: 43). La tradición prometeica, que es la del iluminismo, el positivismo y el socialismo utópico, sostenía los límites de lo que era posible conocer, hacer y crear, preservando el misterio de la vida y la evolución biológica. En cambio, la posición fáustica contemporánea pone el acento en el carácter técnico del conocimiento científico, cuyo fin es ejercer la previsión y el control de los fenómenos naturales, incluidos los de la vida. Reencontramos así la visión de Foucault, quien poniendo de relieve el régimen de poder en que esta posición se sustenta, la denominó biopolítica.

Esta deriva postorgánica toma impulso en lo que Sibilia considera un cambio de paradigma en el modo de entender el cuerpo humano. Según plantea la autora, "[e]n la tecnociencia de inspiración fáustica, la naturaleza ya no se descompone y recrea según el régimen mecánico-geométrico sino de acuerdo con el modelo informático-celular" (Sibilia, 2005: 89). En consecuencia, las nociones de información, código y programación, fuertemente apuntaladas por el proyecto Genoma Humano, propiciaron la idea de un cuerpo postorgánico, definido por la metáfora del "perfil de información". Las relativamente novedosas tecnologías de la comunicación, que propician experiencias virtuales que prescinden de la materialidad del espacio y la linealidad del tiempo y parecen eludir la condición corpórea, han contribuido a afianzar esta idea. Un nuevo personaje, que Sibilia denomina "hombre postorgánico", rompe con la distinción tradicional entre lo natural y lo artificial, y abraza las tendencias virtualizantes y digitalizantes. 
Así, la metáfora maquinal del cuerpo es suplantada por el paradigma de la información, pero en estricto rigor se trata más bien de su corolario. El proceso de descomposición/recomposición mecanicista del cuerpo humano culmina a nivel molecular con el desciframiento del código genético y su decodificación y recodificación mediante herramientas digitales. Se configura así un neocartesianismo "high-tech", en el cual la distinción tradicional entre cuerpo y alma se transforma en el par hardware/software, cuyo fin último es la manipulación y creación de vida.

\section{Consideraciones finales}

Para concluir, es necesario subrayar que el neocartesianismo "high-tech" delimita el contexto de pensamiento en el que las TRHA tienen lugar. En consecuencia, tanto las problemáticas bioéticas como las implicancias subjetivas concomitantes requieren tener en cuenta este panorama, para una mejor compresión y abordaje de las mismas.

Sin embargo, como hemos señalado de entrada, los efectos de las TRHA suelen ser abordados desde la perspectiva de las nuevas configuraciones familiares, lo cual deja los dilemas en torno al tratamiento del cuerpo librados a enfoques de corte moral, que se agotan en posiciones a favor o en contra. En contrapartida, lo que pretendemos aportar con este artículo es una perspectiva que problematiza la relación entre lo "bio" y los avatares de la subjetividad contemporánea, sirviéndonos a tal fin de herramientas de la filosofía, la antropología, las ciencias jurídicas y el psicoanálisis.

Por otra parte, aunque de modo implícito, esta reflexión también arroja luz sobre cuestiones que atañen a dichas configuraciones familiares. De un lado, el modo de concebir y tratar el cuerpo afecta a los donantes de gametos y progenitores, según el modo en que se representan ese material biológico. Del otro, la cuestión también alcanza a los niños nacidos mediante el uso de TRHA, para quienes la manera de concebir el material genético incide sobre un aspecto tan sensible como el de la construcción subjetiva de la identidad.

\section{Referencias Bibliográficas}

AGAMBEN, G. (1998) Homo Sacer. El poder soberano y la nuda vida. Barcelona: Pre-textos.

COSSE, I. (2010) Pareja, sexualidad y familia en los años '60. Buenos Aires: Siglo XXI.

DESCARTES, R. (2010) Discurso del método. Meditaciones metafísicas [1637y 1641]. Madrid: Espasa libros, versión Kindle.

--- (1965 [1637]) Discours de la méthode, nota n.1 a pie de página de la pág. 46. París: J. Vrin.

FOUCAULT, M. (1978) El nacimiento de la clínica. Una arqueología de la mirada médica. Madrid: Siglo XXI.

--- (1984 [2002]) Historia de la sexualidad, Volumen I “La voluntad de saber”. (2ºd.) Buenos Aires: Siglo XXI.

GUIMÓN, P. \& Prats, J. (3 de febrero de 2015): "Reino Unido da luz verde al primer bebé con tres padres genéticos” En El País. http://elpais.com/elpais/2015/02/03/ciencia/1422963738_504035.html 
HERRERA, M. CARAMELO, G. y PICASSO, S. (eds.): Código Civil y Comercial de la Nación Comentado. Tomo II, Libro Segundo. Artículos 401 a 723. Infojus-Dirección Nacional del Sistema Argentino de Legislación Jurídica, 2015.

IACUB, M. (2002) Le crime était presque sexual et autres essais de casuistique juridique. Paris: Flammarion.

LACAN, J. (2008a) "Función y campo de la palabra y el lenguaje en psicoanálisis", En Escritos I. Buenos Aires: Siglo XXI.

---, (2008b): "El estadio del espejo como formador de la función del yo [je] tal como se nos revela en la experiencia anlítica", En Escritos I. Buenos Aires: Siglo XXI.

MARTINS, Hermínio (2011) Experimentum Humanum - civilização tecnológica e condição humana. Lisboa: Relógio D'Água.

NOONAN, H. (2003) Personal Identity. London: Routledge.

PLUTARCO (2011) Vidas paralelas I: Teseo-Rómulo. Madrid: Gredos.

ROSE, N. (2013) "Las políticas de la vida en el siglo XXI", En Quintanas, A. (ed.) (2013): El trasfondo biopolítico de la bioética. Girona: Documenta Universitaria.

ROSE, N (2006) The Politics of Life Itself: Biomedicine, Power and Subjectivity in the Twenty-First Century. London: Princeton University Press.

SIBILIA, P. (2005) El hombre postorgánico: cuerpo, subjetividad y tecnologías digitales. Buenos Aires: Fondo de Cultura Económica. 